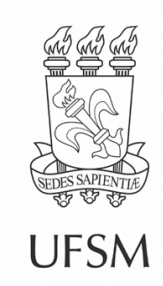

\title{
Artigos
}

\section{Composição química do solo em diferentes condições ambientais}

\author{
Chemical composition of soil in different environmental conditions
}

\author{
Elaine Novak' ${ }^{\oplus}$, Laércio Alves Carvalho" $\oplus^{,}$ \\ Etenaldo Felipe Santiago" ${ }^{\bullet}$, Fabiane Silva Ferreira"' $\odot$, \\ Marina Rodrigues Maestre" ${ }^{\|}$ \\ 'Universidade Estadual de Mato Grosso do Sul, Glória de Dourados, MS, Brasil \\ "Universidade Estadual de Mato Grosso do Sul, Dourados, MS, Brasil \\ I'Pesquisadora Autônoma, Dourados, MS, Brasil
}

\section{RESUMO}

A sustentabilidade ou a degradação de um ambiente podem ser estimadas, entre outros, pela avaliação e monitoramento de atributos do solo, os quais podem evidenciar alterações relacionadas ao uso e manejo ao longo do tempo. Compreender alterações decorrentes de manejo, empregados em diferentes sistemas, pode auxiliar no entendimento dos processos que preconizam a ecologia da restauração. Assim, avaliou-se a qualidade do solo com base em seus atributos químicos em diferentes usos, sendo cinco áreas em processo de restauração ecológica (REC1 a REC5), uma área de vegetação nativa (MATA) e uma de cultivo de cana-de-açúcar (CN), todas localizadas em uma propriedade rural particular no município de Rio Brilhante, MS, Brasil, em uma área de transição entre os Biomas CerradoMata Atlântica. Os atributos químicos avaliados foram: matéria orgânica (MO), pH, capacidade de trocas catiônicas (CTC), soma de bases $(\mathrm{SB})$, potássio $(\mathrm{K})$, fósforo $(\mathrm{P})$, magnésio $(\mathrm{Mg})$, cálcio $(\mathrm{Ca})$, saturação por base (V\%) e acidez potencial ( $\mathrm{H}+\mathrm{Al})$. Os dados foram submetidos à análise multivariada, incluindo a análise de componentes principais (PCA) e análise de agrupamento. A PCA indicou que, dentre as áreas estudadas, a área em restauração ecológica 1 (REC1) apresentou relação negativa com os atributos químicos do solo (exceto com a acidez potencial na camada superficial) e demonstrou maior similaridade com a área de cultivo de cana-de-açúcar. Em contrapartida, a área em restauração ecológica 3 (REC3) apresentou a melhor qualidade química do solo e maior similaridade com área de vegetação nativa, evidenciando, dessa forma, que o desenvolvimento da cobertura vegetal e a ausência de mecanização foram importantes para promover a melhoria da qualidade do solo. Os dados obtidos sugerem que as novas formas de manejo nas áreas em restauração implicam em diferentes níveis de qualidade do sistema solo, tendendo ao aumento da estabilidade e integridade biológica, alterações estas que fazem parte dos processos ecológicos comuns a ecossistemas preservados.

Palavras-chave: Atributos químicos; Restauração ecológica; Vegetação nativa; Sistema produtivo 


\begin{abstract}
The sustainability or degradation of the environment can be estimated, among others, for the evaluation and monitoring of sensitive soil attributes for the use and management over time. Understanding the changes resulting from management uses in different systems can assist in the knowledge of ecological processes that advocate restoration ecology. Thus, the objective of this study was to evaluate the soil quality based on its chemical attributes in different uses, being five areas in ecological restoration, an area of native vegetation and a sugarcane crop, all locations in a rural property in Rio Brilhante city, MS, in a transition area between the Cerrado-Mata Atlântica Biomes. The chemical attributes evaluated were: organic matter (OM), $\mathrm{pH}$, cation exchange capacity (CTC), sum of bases (SB), potassium (K), phosphorus $(\mathrm{P})$, magnesium $(\mathrm{Mg})$, calcium $(\mathrm{V} \%)$ and potential acidity $(\mathrm{H}+\mathrm{Al})$. The data were submitted to multivariate analysis, among them: the principal component analysis (PCA) and clustering. The PCA indicated, among the studied areas, the areas under ecological restoration 1 (REC1) presented a lower relation with soil chemical attributes (except for the potential acidity in the surface layer) and showed greater similarity with a sugarcane cultivation area. On the other hand, REC3 presented a better soil chemical quality and greater similarity with native vegetation area, thus evidencing that the vegetation cover development and a mechanization absence were important to promote an improvement of soil quality. The data obtained suggest that the new forms of management in restoration areas imply different levels of soil system quality, tending to increase stability and biological integrity, changes that are part of the ecological processes common to preserved ecosystems.
\end{abstract}

Keywords: Chemical attributes; Ecological restoration; Native vegetation; Production system

\title{
1 INTRODUÇÃO
}

A remoção da cobertura vegetal e a implantação de atividades agropecuárias podem provocar desequilíbrios nos ecossistemas em virtude dos tipos de manejo empregados (FREITAS et al., 2015). Os efeitos de manejo inadequado, sobretudo na qualidade do solo, são evidenciados pela diminuição de sua fertilidade e alteração de seus atributos (PORTUGAL; COSTA; COSTA, 2010), além da redução na diversidade biológica, fatores que, em maior ou menor grau, reduzem as oportunidades e flexibilidades relacionadas aos serviços ecossistêmicos (NOVAK, 2017).

O estado de Mato Grosso do Sul apresenta um perfil agropecuário de grande importância para a economia nacional, com destaque na produção de proteína animal, grãos e na cultura da cana-de-açúcar, esta última com produção média superior a 46 milhões de toneladas, para uma área plantada média pouco superior a $626 \mathrm{mil}$ ha, para a série histórica 2014-2017 (IBGE, 2019). Se por um lado, os sistemas de produção 
indicam o potencial econômico e social de tais atividades; por outro, há vulnerabilidade dos ecossistemas naturais aos processos de degradação, principalmente àqueles inerentes à abertura de novas áreas e ao uso e ocupação do solo de forma inadequada (NOVAK, 2017).

Em cumprimento ao Código Florestal Brasileiro em sua recente versão (Lei 12.651 de 25 de maio de 2012), muitas propriedades rurais, para serem consideradas regulares, necessitam de um plano de recuperação de áreas degradadas (PRAD) considerando a obrigatoriedade da recomposição florestal de áreas manejadas de forma inadequada (BRASIL, 2012). Todavia, a restauração de áreas degradadas envolve uma série de medidas que buscam, inicialmente, minimizar os efeitos da degradação e, posteriormente, implantar metodologias corretivas que contribuam para o reestabelecimento de funções que foram perdidas (NOVAK et al., 2017).

A adoção de medidas mitigadoras deve ser precedida da avaliação dos atributos do solo, pois esta implica no diagnóstico edáfico atual, colaborando tanto para o entendimento dos fatores de sua degradação, quanto para a definição de métodos adequados às condições específicas do local ou da região (AUDEH et al., 2011), tendo como resultado o melhor planejamento das práticas de restauração. Dessa forma, o sucesso dos programas de restauração não pode ser avaliado apenas pela velocidade de formação da cobertura vegetal, mas também por meio do monitoramento dos diferentes atributos do solo considerados como indicadores de qualidade e/ou degradação ambiental.

A sustentabilidade ou a degradação de um ambiente podem ser estimadas, entre outros, pela avaliação e monitoramento de atributos do solo sensíveis às alterações pelo uso e manejo ao longo do tempo, tais como pH, saturação por bases e teores de nutrientes (NASCIMENTO et al., 2014) entre outros atributos químicos. Compreender as interações entre a biodiversidade vegetal, as propriedades químicas e os efeitos das alterações no solo são fundamentais nas práticas de restauração em áreas degradadas (MUELLER et al., 2014). Em longo prazo, essas avaliações servem como instrumento para o monitoramento da conservação ambiental, pois permitem caracterizar a 
situação atual, alertar para situações de risco e, por vezes, prever situações futuras, especialmente quando a vegetação nativa é adotada como ecossistema de referência (CARDOSO et al., 2011).

O emprego de métodos estatísticos multivariados em estudos sobre a qualidade do solo em sistemas agrícolas, ecossistemas naturais (CASTILHOS et al., 2015), antropizados ou em processo de recuperação (FREITAS et al., 2015; YADA et al., 2015), vem crescendo nos últimos anos. Esse tipo de análise permite descrever os eventos atuantes sobre os conjuntos de dados em nível de significância conhecido, permitindo assim maior compreensão da distribuição geral dos resultados e as suas relações (PAYE; MELLO; MELO, 2012).

Quando aplicada a dados do solo, a análise multivariada também auxilia na tomada de decisão acerca do uso e manejo adequados deste sistema, baseando-se no comportamento dos seus atributos, e indica aqueles que sofrem maior alteração com a ação antrópica (OLIVEIRA et al., 2015). São análises que descrevem as variáveis químicas do solo que explicam a maior variabilidade possível em um conjunto de dados (componentes principais) (CORTEZ et al., 2011) e possibilitam a caracterização e agrupamento de diferentes sistemas pelo seu grau de similaridade, explicando, dessa forma, o máximo de interação e correlação entre as variáveis, demonstrando ainda quais delas contribuem mais para a caracterização e/ou explicam as alterações do solo (OLIVEIRA et al., 2015).

Sendo assim, este trabalho tem como objetivo avaliar a qualidade do solo com base nos atributos químicos em diferentes usos por meio de métodos estatísticos multivariados, como forma de discutir os efeitos do manejo sobre a integridade deste sistema. São pressupostos deste estudo que os impactos do cultivo de cana-de-açúcar, onde houve uso intensivo de fertilizantes associados à mecanização, tenham reflexos sobre a qualidade do sistema solo, assim, compreender as alterações decorrentes do manejo empregado nas áreas avaliadas é fundamental ao entendimento dos processos ecológicos que preconizam a ecologia da restauração. Nesse sentido, as respostas das seguintes questões poderão contribuir para o melhor entendimento e planejamento das práticas de restauração: As áreas analisadas a presentam diferenças na composição 
química do solo? As áreas em restauração ecológica apresentam evolução substancial na qualidade química do solo? As áreas em restauração assemelham-se à área de vegetação nativa ou à área cultivada?

\section{MATERIAL E MÉTODOS}

\subsection{Caracterização da área de estudo}

O trabalho foi conduzido no município de Rio Brilhante, Estado de Mato Grosso

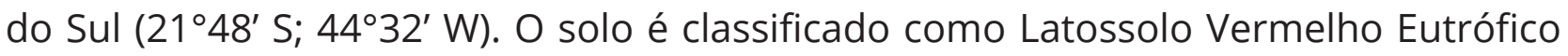
típico, de textura argilosa (EMBRAPA, 2013). De acordo com o sistema de classificação Köppen (Cwa), o clima é caracterizado como mesotérmico úmido, com verões quentes e invernos secos (Figura 1).

Figura 1 - Valores médios mensais de precipitação pluvial das áreas avaliadas

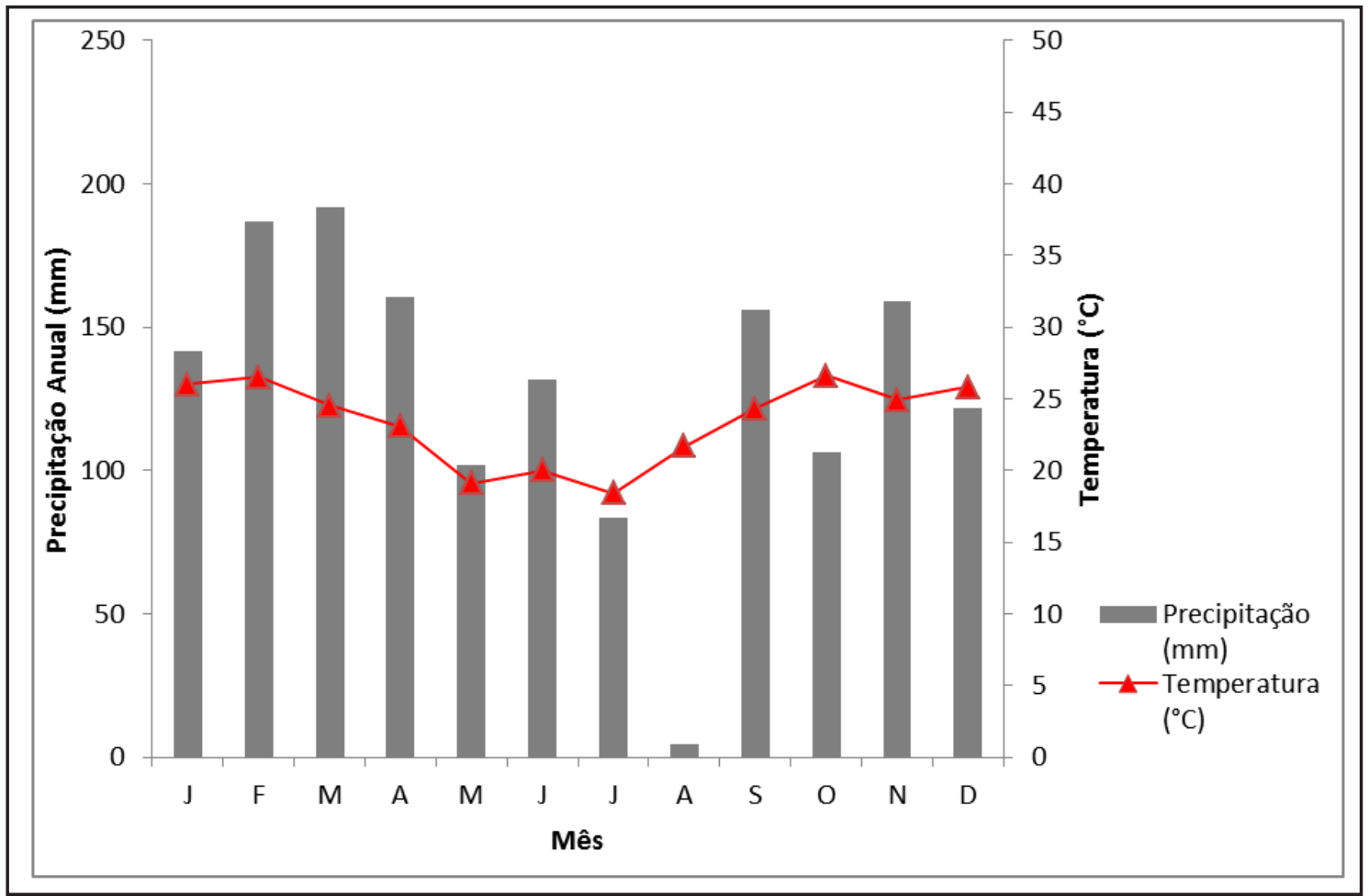

Fonte: Autores (2015)

Em que: *As letras representam as iniciais de cada mês, de janeiro a dezembro. Dados adaptados de EMBRAPA-CPAO, Dourados, MS, 2014. 
Para comparação da composição química do solo em diferentes condições ambientais, as unidades amostrais compreenderam: a) Uma área remanescente composta por vegetação nativa, com fisionomia florística típica de área de transição entre Cerrado e Mata Atlântica, denominada MATA(ecossistema de referência); b) Cinco áreas em restauração ecológica, identificadas como REC1 a REC5, respectivamente; e c) Uma área de cultivo de cana-de-açúcar (CN); compreendendo um total de 07 (sete) unidades amostrais (Figura 2).

Figura 2 - Mapa de localização elaborado no Quantum QGis 14.2

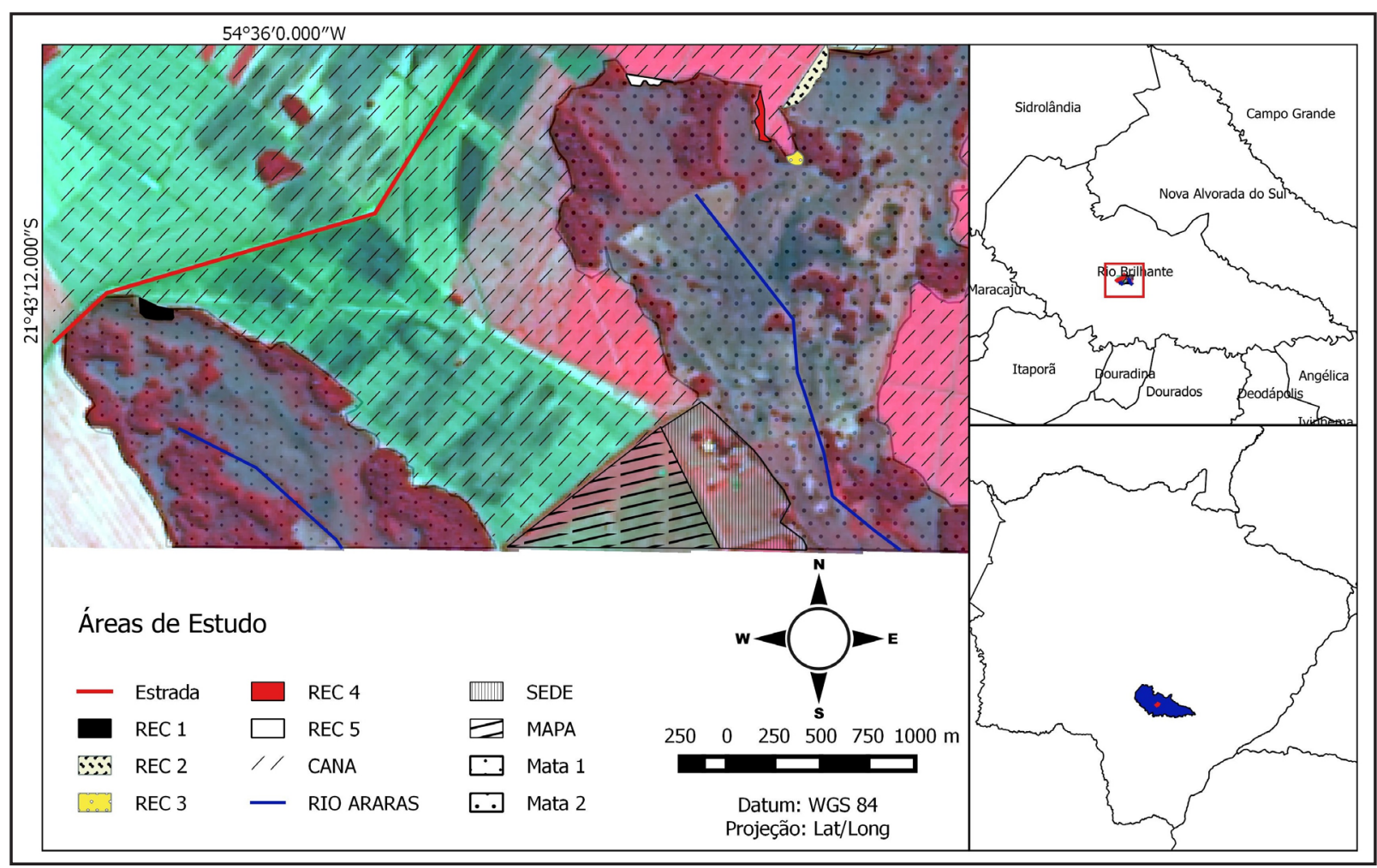

Fonte: Autores (2017)

As áreas em restauração foram estabelecidas em formação originalmente de floresta estacional semidecidual e substituída por pastagem (Brachiaria brizantha) manejadas num período de dez anos e, posteriormente, por cana-de-açúcar num período de 2 anos. Após esse período, as áreas foram destinadas à restauração ambiental. Devido à localização, as áreas em restauração foram identificadas como 
REC1 a REC5, com adoção de regeneração natural e plantio de espécies nativas florestais, tais como: Myracrodruon urundeuva, Schinus terebinthifolius, Handroanthus avellanedae, Machaerium stipitatum e Dalbergia miscolobium, entre outras, na área identificada como REC2, e regeneração natural nas demais áreas, ressaltando que em nenhuma das áreas houve intervenção mecânica e aplicação de fertilizantes.

O plantio da cana-de-açúcar (RB86 - 7515) foi realizado com preparo convencional do solo utilizando duas gradagens (grades aradoras), uma subsolagem até a profundidade de $45 \mathrm{~cm}$ e uma gradagem niveladora. Foi utilizado fertilizante mineral $\mathrm{N}-\mathrm{P}_{2} \mathrm{O}_{5} \mathrm{~K}_{2} \mathrm{O}$ (05-15-10) durante o plantio da cultura, e nos cortes anuais a reposição foi feita utilizando fertilizante mineral $\mathrm{N}-\mathrm{P}_{2} \mathrm{O}_{5} \mathrm{~K}_{2} \mathrm{O}(30-05-25)$ na linha da cultura. Nos tratos culturais da cana soca foram realizadas operações de cultivo entre linhas da cultura (subsolagem e sulcador), visando a minimizar os efeitos da compactação do solo causada pelo intensivo tráfego de máquinas na colheita. Na época de amostragem (período chuvoso 2014), a cultura de cana-de-açúcar encontrava-se no quarto corte de colheita mecanizada.

\subsection{Delineamento experimental e procedimento laboratorial}

Para avaliação dos atributos químicos do solo, amostras simples foram coletadas no período chuvoso de 2014 (entre os meses de setembro a dezembro), nas camadas de $0-10 \mathrm{~cm}$ e $10-20 \mathrm{~cm}$ seguindo o delineamento inteiramente casualizado (DIC) com quatro repetições aleatórias em cada área e camada estudada. As amostras coletadas foram armazenadas em sacos plásticos identificados e encaminhadas ao laboratório de química de solo da Embrapa Agropecuária Oeste, Dourados, MS.

As análises químicas foram realizadas no laboratório seguindo métodos descritos pela EMBRAPA (Empresa Brasileira de Pesquisa Agropecuária) (EMBRAPA, 1997). Foram estimados os valores para cálcio $\left(\mathrm{Ca}^{2+}\right)$, magnésio $\left(\mathrm{Mg}^{2+}\right)$, potássio $\left(\mathrm{K}^{+}\right)$, acidez potencial $(\mathrm{H}+\mathrm{Al})$, soma de bases $(\mathrm{SB})$, capacidade de troca catiônica (CTC), matéria orgânica $(\mathrm{MO})$, saturação por bases $(\mathrm{V} \%)$, fósforo $(\mathrm{P})$ e $\mathrm{pH}\left(\mathrm{CaCl}_{2}\right)$ em ambas as camadas. 


\subsection{Análise exploratória dos dados}

Os dados obtidos foram padronizados para obter médias zero e desvio-padrão unitários (MANLY, 2008) essenciais na análise multivariada.

Com o objetivo de reduzir a dimensionalidade do conjunto de variáveis e facilitar a interpretação da independência entre elas (JOSÉ et al., 2013) e identificar quais variáveis explicam a maior parte da variabilidade dos dados foi utilizada uma análise de componentes principais (PCA), na qual utilizou-se a média da composição química do solo em diferentes condições ambientais (MATA, REC1-5 e CN). A análise de PCA foi realizada utilizando a função "prcomp" no pacote "vegan" (OKSANEN et al., 2006) no software R (R DEVELOPMENT CORE TEAM, 2015).

A significância da influência das variáveis químicas do solo entre as áreas avaliadas foi quantificada por meio da função "envfit" no software "vegan" (OKSANEN et al., 2006) que após a obtenção de um valor de $r^{2}$ (coeficiente de determinação) para as variáveis químicas utilizou um processo de randomização para definir a significância destas (999 permutações) para os eixos da PCA.

Para a seleção dos componentes principais mais significativos e representativos seguiu-se o critério estabelecido por Kaiser (1958), que consiste em incluir apenas os componentes cujos valores sejam superiores a 1. O critério de classificação de cada variável na matriz constituinte dos componentes principais foi estabelecido por Coelho et al. (2003), adotando-se o valor absoluto $<0,30$ como pouco significativo; 0,30-0,40 mediano; e $\geq 0,50$ altamente significativo.

Para verificar o padrão da variação da composição química do solo em diferentes condições ambientais (MATA, REC1-5 e CN) foi utilizada uma análise de agrupamento (cluster analysis), por meio do método "vizinho mais distante" (complete linkage) utilizando o coeficiente de distância eucliadiana (LANDIM, 2011) para determinar os cortes na formação dos agrupamentos. 


\section{RESULTADOS E DISCUSSÃO}

A tabela 1 apresenta a média dos valores de cálcio $\left(\mathrm{Ca}^{2+}\right)$, magnésio $\left(\mathrm{Mg}^{2+}\right)$, potássio $\left(\mathrm{K}^{+}\right)$, acidez potencial $(\mathrm{H}+\mathrm{Al})$, soma de bases $(\mathrm{SB})$, capacidade de troca catiônica (CTC), matéria orgânica (MO), saturação por bases (V\%), fósforo (P) e pH $\left(\mathrm{CaCl}_{2}\right)$, em ambas as camadas, utilizados para a construção da matriz para análise multivariada.

Tabela 1 - Médias dos valores atributos químicos do solo nas camadas 0-10 cm e 10-20 cm nas áreas em restauração ecológica, vegetação nativa e cultivo de cana-de-açúcar

\begin{tabular}{|c|c|c|c|c|c|c|c|c|c|c|}
\hline \multirow{2}{*}{ Áreas } & $\mathrm{pH}$ & MO & $\mathbf{P}$ & $\mathbf{K}$ & $\mathrm{Ca}$ & Mg & $\mathrm{H}+\mathrm{Al}$ & SB & CTC & $\mathbf{V}$ \\
\hline & $\left(\mathrm{CaCl}_{2}\right)$ & $\mathrm{g} \mathrm{dm}^{-3}$ & $\left(\mathrm{~g} \mathrm{~m}^{-3}\right)$ & \multicolumn{6}{|c|}{$\mathrm{cmol}_{\mathrm{c}} \mathrm{dm}^{-3}$} & $\%$ \\
\hline \multicolumn{11}{|c|}{ Camada $0-10 \mathrm{~cm}$} \\
\hline $\mathrm{CN}$ & 5,5 & 42,95 & 0,92 & 0,38 & 7,25 & 2,17 & 4,26 & 9,81 & 14,08 & 69,62 \\
\hline MATA & 5,8 & 62,76 & 1,85 & 0,39 & 9,35 & 3,20 & 3,97 & 12,94 & 16,92 & 76,14 \\
\hline REC1 & 5,4 & 48,12 & 0,97 & 0,26 & 8,10 & 2,87 & 4,52 & 11,24 & 15,76 & 71,42 \\
\hline REC2 & 5,6 & 55,22 & 2,62 & 0,41 & 9,00 & 3,20 & 3,72 & 12,61 & 16,34 & 77,13 \\
\hline REC3 & 5,3 & 55,42 & 0,75 & 0,54 & 8,32 & 2,87 & 5,10 & 11,74 & 16,84 & 69,53 \\
\hline REC4 & 5,6 & 53,75 & 0,87 & 0,38 & 8,85 & 2,95 & 3,87 & 12,18 & 16,06 & 75,82 \\
\hline REC5 & 5,8 & 48,92 & 1,10 & 0,35 & 7,87 & 2,85 & 3,36 & 11,07 & 14,43 & 76,63 \\
\hline \multicolumn{11}{|c|}{ Camada $10-20 \mathrm{~cm}$} \\
\hline $\mathrm{CN}$ & 5,5 & 37,30 & 0,62 & 0,22 & 6,37 & 1,90 & 3,96 & 8,50 & 12,46 & 68,25 \\
\hline MATA & 5,3 & 48,99 & 1,15 & 0,22 & 7,55 & 2,65 & 3,93 & 10,42 & 16,61 & 63,34 \\
\hline REC1 & 5,2 & 44,13 & 0,72 & 0,18 & 7,92 & 2,40 & 4,75 & 10,51 & 15,26 & 68,86 \\
\hline REC2 & 5,5 & 47,12 & 0,70 & 0,31 & 8,07 & 2,52 & 4,03 & 10,91 & 14,94 & 72,76 \\
\hline REC3 & 5,3 & 51,20 & 0,47 & 0,25 & 8,67 & 2,62 & 5,11 & 11,55 & 16,66 & 69,22 \\
\hline REC4 & 5,5 & 48,92 & 0,75 & 0,25 & 8,47 & 2,70 & 4,24 & 11,43 & 15,66 & 72,82 \\
\hline REC5 & 5,8 & 43,55 & 0,87 & 0,24 & 7,80 & 2,52 & 3,33 & 10,57 & 13,90 & 75,85 \\
\hline
\end{tabular}

Fonte: Autores (2017)

Em que: $\mathrm{REC1}$ = área em restauração ecológica 1; REC2 = área em restauração ecológica 2; REC3 = área em restauração ecológica 3; REC4 = área em restauração ecológica 4; REC5 = área em restauração ecológica 5; $\mathrm{CN}$ = cana-de-açúcar; $\mathrm{MATA}=$ fragmento de vegetação nativa de Floresta Estacional Semidecidual; $\mathrm{pH}=$ potencial hidrogeniônico; $\mathrm{MO}=$ matéria orgânica; $\mathrm{P}=$ fósforo, $\mathrm{K}$ = potássio; $\mathrm{Ca}$ = cálcio; $\mathrm{Mg}$ = magnésio; $\mathrm{H}+\mathrm{Al}$ = acidez potencial; $\mathrm{SB}$ = soma de bases; CTC = capacidade de troca catiônica; V\% = saturação por bases.

Na camada superficial, a análise de componentes principais (PCA) indicou que os dois primeiros eixos explicaram $59,4 \%$ e $26,5 \%$ da variância, respectivamente. A 
soma de bases (SB) apresentou maior associação negativa $(-0,399)$ no primeiro eixo, enquanto que $\mathrm{H}+\mathrm{Al}$ apresentou maior associação positiva $(0,554)$ no segundo eixo (Tabela 2).

Os autovetores dos dois primeiros eixos da PCA explicaram $85,6 \%$ da variabilidade dos dados na camada superficial, sendo que a carga fatorial de cada variável no primeiro componente principal (CP1) apresentou significância mediana a baixa, pois os autovalores (escores) encontraram-se abaixo de 0,5 (COELHO, 2003). As variáveis que apresentaram cargas fatoriais abaixo desses valores são aquelas que retêm pequena parte da variação total contribuindo em menor proporção para discriminar o uso do solo (PRAGANA et al., 2012). No segundo componente principal (CP2), apenas acidez potencial $(\mathrm{H}+\mathrm{Al})$ apresentou alta significância $(\geq 0,50)$ (Tabela 2$)$.

Tabela 2 - Análise dos componentes principais dos atributos químicos do solo das áreas avaliadas na camada de 0-10 cm

\begin{tabular}{lcc}
\hline & \multicolumn{2}{c}{ Componentes principais } \\
\cline { 2 - 3 } \multicolumn{1}{c}{ Componentes de variância } & Eixo 1 & Eixo 2 \\
\hline Autovalores & 0,594 & 0,265 \\
Proporção \% & 59,4 & 26,5 \\
Proporção acumulada \% & 59,4 & 85,9 \\
\hline Variáveis & Correlação com os componentes principais* \\
\hline pH & $-0,309$ & $-0,341$ \\
Ca & $-0,393$ & 0,114 \\
Mg & $-0,389$ & 0,050 \\
H+Al & 0,152 & 0,554 \\
K & $-0,061$ & 0,429 \\
P & $-0,289$ & $-0,123$ \\
SB & $-0,399$ & 0,126 \\
CTC & $-0,301$ & 0,403 \\
V\% & $-0,322$ & $-0,367$ \\
MO & $-0,369$ & 0,221 \\
\hline
\end{tabular}

Fonte: Autores (2017)

Em que: * Coeficientes de correlação com as variáveis originais padronizadas. Número em negrito indica a variável com maior carga fatorial (escores) dentro de cada fator. Critério de classificação: valor absoluto $<0,30$, considerado pouco significativo; 0,30-0,40, mediamente significativo; e $\geq 0,50$, altamente significativo. Em que: $\mathrm{pH}$ = potencial hidrogeniônico; $\mathrm{MO}=$ matéria orgânica; $\mathrm{P}=$ fósforo, $\mathrm{K}=$ potássio; $\mathrm{Ca}$ = cálcio; $\mathrm{Mg}$ = magnésio; $\mathrm{H}+\mathrm{Al}$ = acidez potencial; $\mathrm{SB}=$ soma de bases; $\mathrm{CTC}$ = capacidade de troca catiônica; V\% = saturação por bases. 
A soma da variabilidade retida nos componentes explicou $85,9 \%$ da variabilidade original dos dados referentes aos efeitos das diferentes áreas sobre as variáveis químicas do solo, em que PC1 e PC2 retiveram 59,4\% e 26,5\%, respectivamente, das informações originais dos dados na camada superficial (Tabela 2 e Figura 3). As áreas em restauração ecológica, cultivo de cana-de-açúcar e vegetação nativa influenciaram os atributos químicos do solo, conforme indicado pela intercorrelação entre as variáveis do solo e as áreas avaliadas (Figura 3). Contudo, das dez variáveis químicas analisadas, fósforo e potássio não influenciaram significativamente a qualidade do solo na camada superficial destas áreas (Tabela 3).

Figura 3 - PCA dos atributos químicos do solo na camada de 0-10 cm em áreas com restauração ecológica, cultivo de cana-de-açúcar e vegetação nativa

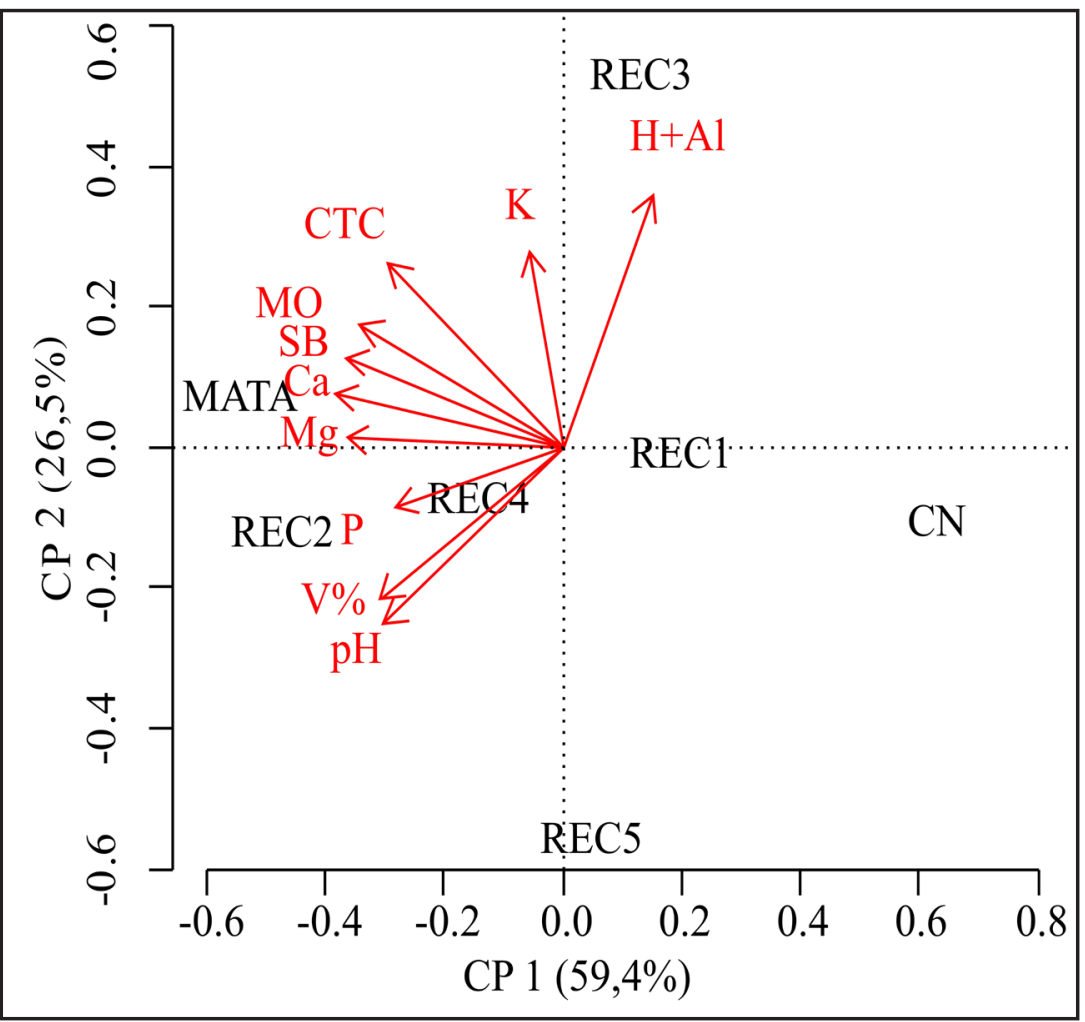

Fonte: Autores (2017)

Em que: $\mathrm{CP}=$ componentes principais; $\mathrm{REC1}$ = área em restauração ecológica 1; REC2 = área em restauração ecológica 2; REC3 = área em restauração ecológica 3; REC4 = área em restauração ecológica 4; REC5 = área em restauração ecológica 5; CN = Cana-de-açúcar; MATA = fragmento de vegetação nativa. 
Tabela 3 - Resultado da significância da análise dos componentes principais (PCA) dos atributos químicos do solo nas camadas de $0-10 \mathrm{~cm}$ e $10-20 \mathrm{~cm}$

\begin{tabular}{lcccccccc}
\hline \multicolumn{7}{c}{ Camada 0-10 cm } & \multicolumn{5}{c}{ Camada 10-20 cm } \\
\hline Variável & CP1 & CP2 & $\mathbf{r}^{2}$ & $\mathbf{P r}(>\mathbf{r})$ & CP1 & CP2 & $\mathbf{r}^{2}$ & Pr(>r) \\
\hline pH & $-0,66488$ & $-0,74695$ & 0,8657 & $0,023^{*}$ & 0,31002 & $-0,95073$ & 0,9387 & $0,002^{*}$ \\
Ca & $-0,95813$ & 0,28632 & 0,9560 & $0,002^{*}$ & $-0,94164$ & $-0,33661$ & 0,9358 & $0,005^{*}$ \\
Mg & $-0,99279$ & 0,11986 & 0,9054 & $0,013^{*}$ & $-0,93623$ & $-0,35138$ & 0,8783 & $0,019^{*}$ \\
H+Al & 0,26921 & 0,96308 & 0,9421 & $0,005^{*}$ & $-0,55956$ & 0,82879 & 0,6478 & $0,117^{\text {ns }}$ \\
K & $-0,13057$ & 0,99144 & 0,4999 & $0,216^{\text {ns }}$ & $-0,28048$ & $-0,95986$ & 0,5452 & $0,219^{\text {ns }}$ \\
P & $-0,91093$ & $-0,41256$ & 0,5352 & $0,260^{\text {ns }}$ & 0,90111 & 0,43360 & 0,0004 & $0,999^{\text {ns }}$ \\
SB & $-0,95014$ & 0,31183 & 0,9879 & $0,002^{*}$ & $-0,92876$ & $-0,37068$ & 0,9785 & $0,003^{*}$ \\
CTC & $-0,59513$ & 0,80363 & 0,9661 & $0,001^{*}$ & $-0,92919$ & 0,36960 & 0,9450 & $0,003^{*}$ \\
V\% & $-0,66508$ & $-0,74677$ & 0,9650 & $0,004^{*}$ & 0,00905 & $-0,99996$ & 0,7793 & $0,046^{*}$ \\
MO & $-0,85621$ & 0,51662 & 0,9379 & $0,003^{*}$ & $-0,99912$ & $-0,04191$ & 0,9521 & $0,003^{*}$ \\
\hline
\end{tabular}

Fonte: Autores (2017)

Em que: $\mathrm{CP}=$ componente principal; $\mathrm{ns}=$ não significativo; * significativo a 0,05\%; $\mathrm{r}^{2}=$ coeficiente de determinação; $\operatorname{Pr}(>\mathrm{r})$ = significância; $\mathrm{Em}$ que: $\mathrm{pH}$ = potencial hidrogeniônico; $\mathrm{MO}=$ matéria orgânica; $\mathrm{P}$ = fósforo, $\mathrm{K}$ = potássio; $\mathrm{Ca}$ = cálcio; $\mathrm{Mg}$ = magnésio; $\mathrm{H}+\mathrm{Al}=$ acidez potencial; $\mathrm{SB}$ = soma de bases; $C T C$ = capacidade de troca catiônica; V\% = saturação por bases.

Os conteúdos de $\mathrm{Ca}, \mathrm{K}, \mathrm{Mg}$, o complexo sortivo (SB e CTC) e MO relacionam-se entre si e em relação oposta às características do complexo de acidez do solo $(\mathrm{H}+\mathrm{Al})$, as quais formam grupos distintos relacionados à MATA e REC3, respectivamente (Figura 3). Esses resultados demonstram a dinâmica natural do solo, na qual o conteúdo dos cátions básicos e a reatividade do complexo sortivo estão relacionados com o conteúdo de matéria orgânica. Essa relação é ainda mais dependente da matéria orgânica em solos com baixos teores de argila e com cobertura florestal, nos quais a deposição de serapilheira é fundamental para a ciclagem biogeoquímica (ROVEDDER et al., 2014), como reportado por Sobral et al. (2015) que encontraram forte influência da composição granulométrica influenciando a dinâmica do carbono no solo. Além disso, Morais, Pissarra e Reis (2012) enfatizam que o fato da área sob vegetação nativa apresentar uma maior diversidade de espécies vegetais que nos demais sistemas acarreta na deposição de substratos orgânicos oxidáveis com composição variada 
na serapilheira. A maior relação com a MO deve-se também ao fato desta estar diretamente associada à baixa interferência antrópica, sem o uso de implementos agrícolas e de tratos culturais (CARNEIRO et al., 2009), possibilitando a mineralização mais lenta da MO e maiores teores de biomassa microbiana acumulados ao longo do perfil do solo, refletindo em maior equilíbrio do ecossistema.

Na MATA, é possível verificar grande influência de MO e CTC, indicando que a remoção da vegetação nativa e a utilização agrícola reduziram os teores de carbono orgânico no solo, como reportado por Freitas et al. (2015). Esses resultados também estão de acordo com Portugal, Costa e Costa (2010), segundo os quais pode haver um declínio no estoque de matéria orgânica após a conversão de florestas nativas em sistemas agrícolas. Os autores ainda enfatizam que essa redução pode ser atribuída ao aumento da erosão do solo, aos processos mais acelerados de mineralização da matéria orgânica do solo e a menores quantidades de aportes orgânicos em sistemas manejados Em áreas de intenso manejo, a cobertura vegetal nativa contribui para o aumento da matéria orgânica do solo e redução da compactação deste sistema (TEFERI; BEWKWT; SIMANE, 2016).

As áreas em restauração ecológica REC2 e REC4 formaram um grupo relacionado à característica da solução do solo, como pH e ao V\% e P. As áreas REC1, REC5 e CN não apresentaram influência sobre a característica química do solo na camada superficial. Esses resultados indicam que o maior equilíbrio e a diversidade de fatores (florística, hifas fúngicas e serapilheira na superfície do solo) nos ecossistemas naturais favorecem a manutenção dos atributos químicos do solo (ALVES et al., 2011).

Na camada $10-20 \mathrm{~cm}$, os autovetores dos dois primeiros eixos da PCA foram 2,223 e 1,637, respectivamente. A soma da variabilidade retida nos componentes explicou 76\% da variabilidade original dos dados, em que, PC1 e PC2 retiveram 49,4\% e 26,6\% das informações originais dos dados, respectivamente (Tabela 4 e Figura 4). Contudo, das dez variáveis químicas analisadas, acidez potencial, fósforo e potássio não influenciaram significativamente a qualidade do solo (Tabela 3). 
Na PCA, além dos cátions básicos Ca e Mg, SB, CTC e MO apresentaram significância moderada no CP1. No segundo componente principal (CP2), pH e V\% apresentaram alta carga fatorial (Tabela 4), corroborando com Silva et al. (2010), Alves et al. (2014) e Silva et al. (2014) que também encontraram componentes principais correlacionados com a acidez do solo.

Tabela 4 - Análise dos componentes principais dos atributos químicos do solo na camada de $10-20 \mathrm{~cm}$

\begin{tabular}{lcc}
\hline \multicolumn{1}{c}{ Componentes de variância } & \multicolumn{2}{c}{ Componentes principais } \\
\hline Autovalores & 2,223 & CP 2 \\
Proporção \% & 49,4 & 1,631 \\
Proporção acumulada \% & 49,4 & 26,6 \\
\hline Variáveis & Correlação com os componentes principais* \\
\hline pH & 0,176 & $-0,543$ \\
Ca & $-0,421$ & $-0,152$ \\
Mg & $-0,407$ & $-0,151$ \\
H+Al & $-0,244$ & $-0,364$ \\
K & $-0,124$ & $-0,420$ \\
P & 0,009 & 0,005 \\
SB & $-0,427$ & $-0,169$ \\
CTC & $-0,420$ & 0,168 \\
V\% & 0,004 & $-0,541$ \\
MO & $-0,439$ & $-0,017$ \\
\hline
\end{tabular}

Fonte: Autores (2017)

Em que: * Coeficientes de correlação com as variáveis originais padronizadas. Números em negrito indicam as variáveis com maior carga fatorial (escores) dentro de cada fator. Critério de classificação: valor absoluto $<0,30$, considerado pouco significativo; 0,30-0,40, mediamente significativo; e $\geq 0,50$, altamente significativo. $\mathrm{Em}$ que: $\mathrm{pH}=$ potencial hidrogeniônico; $\mathrm{MO}=$ matéria orgânica; $\mathrm{P}=$ fósforo, $\mathrm{K}$ = potássio; $\mathrm{Ca}$ = cálcio; $\mathrm{Mg}$ = magnésio; $\mathrm{H}+\mathrm{Al}=$ acidez potencial; $\mathrm{SB}$ = soma de bases; $\mathrm{CTC}$ = capacidade de troca catiônica; V\% = saturação por bases.

Analisando a Figura 4 e seus respectivos eixos, foi observado que as áreas em restauração ecológica REC1 e REC3, e MATA se posicionaram no quadrante superior esquerdo da linha vertical, enquanto no quadrante inferior esquerdo encontram-se REC2 e REC4. As áreas REC5 e CN situam-se no quadrante direito inferior e superior, respectivamente. 
A área em processo de restauração REC3 e a MATA tiveram maior correlação com a CTC e com o complexo de acidez $(\mathrm{H}+\mathrm{Al})$ do que com os demais atributos químicos do solo, REC5 associou-se com o pH do solo, e REC2 e REC4 com as variáveis relacionadas à fertilidade do solo, como os cátions básicos $\left(\mathrm{Ca}^{2+}, \mathrm{Mg}^{2+}, \mathrm{K}^{+}\right), \mathrm{SB}, \mathrm{MO}$ e $\mathrm{V} \%$. A área de cultivo de cana-de-açúcar (CN) apontou pequena associação com fósforo, contudo, observa-se que este atributo não apresentou importância significativa (Tabela 3) para a explicação dos dados. Apesar disso, a aplicação de fertilizantes minerais e resíduos orgânicos em áreas de cultivo de cana-de-açúcar promove aumento no teor de fósforo e aumento ou manutenção do nível de potássio no solo (CHERUBIN et al., 2016).

Figura 4 - PCA dos atributos químicos do solo na camada de 10-20 cm em áreas com restauração ecológica, cultivo de cana-de-açúcar e vegetação nativa

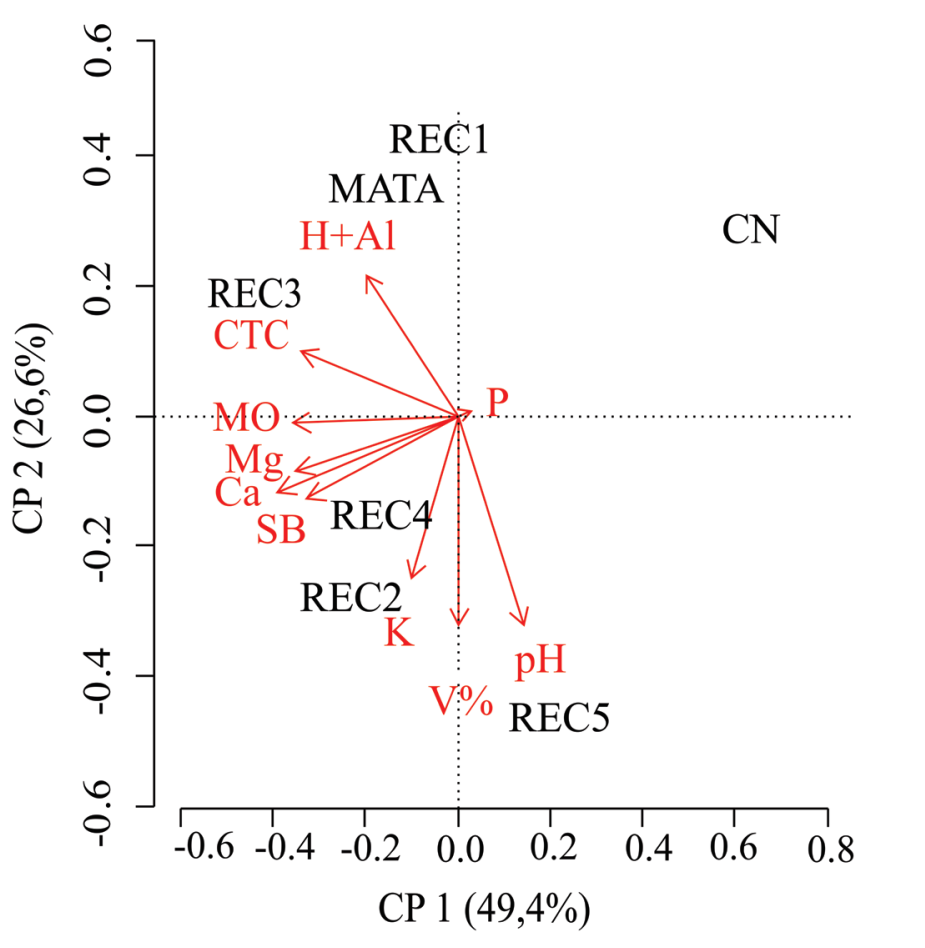

Fonte: Autores (2017)

Em que: $\mathrm{CP}=$ componentes principais; $\mathrm{REC1}=$ área em restauração ecológica $1 ; \operatorname{REC2~=~área~em~restauração~}$ ecológica 2; REC3 = área em restauração ecológica 3; REC4 = área em restauração ecológica 4; $\mathrm{REC5}$ = área em restauração ecológica 5; CN = cana-de-açúcar; MATA = fragmento de vegetação nativa. 
Resultado similar foi encontrado por Oliveira et al.(2015), que também verificaram que o solo em áreas de vegetação nativa e com cultivo agroflorestal apresentaram forte associação com acidez potencial do solo. Em solos naturais ou em processo de recuperação, a acidez potencial do solo pode estar relacionada à lixiviação ou à adsorção de cátions de caráter básico do complexo de troca, como $\mathrm{Ca}^{2+}, \mathrm{Mg}^{2+}, \mathrm{K}^{+}$e $\mathrm{Na}^{+}$, e o consequente acúmulo de cátions de natureza ácida, como $\mathrm{Al}^{3+} \mathrm{e} \mathrm{H}^{+}$.

Em solos mais argilosos (como das áreas de estudo), a acidez potencial pode estar relacionada à decomposição da matéria orgânica e dos resíduos vegetais, bem como à ionização de seus ácidos carboxílicos, fenólicos e álcoois terciários no estágio inicial da mineralização, fatores que contribuem para acidez do solo (SOUSA; MIRANDA; OLIVEIRA, 2007), devido à formação de complexos orgânicos hidrossolúveis entre Ca²+ e $\mathrm{Mg}^{2+}$ com ligantes orgânicos (MIYAZAWA; PAVAN; CALEGARI, 1993).

Os processos de decomposição da MO, e consequente ionização de compostos, seguidos da percolação de cátions no perfil do solo (FRANCHINI et al., 1999), estão relacionados à acidificação do sistema, comprovada no estudo de Ebeling et al. (2008), que encontraram correlação positiva entre o teor de matéria orgânica e acidez potencial em Organossolo.

Os resultados obtidos em nosso estudo demonstraram que, dentre as áreas em processo de restauração ecológica, REC1 apresentou menor correlação com os atributos químicos do solo e, consequentemente, maior similaridade com CN. As demais áreas em restauração apresentaram maiores correlações com os atributos químicos do solo, o que pode estar relacionado à maior riqueza e diversidade de espécies arbóreas que implicam numa deposição contínua de substratos orgânicos com composição variada na serapilheira (SOUZA et al., 2012), favorecendo a ciclagem de nutrientes nesses ambientes. 
Com a análise de agrupamento hierárquico para o conjunto de atributos químicos estudados, foi possível a divisão de grupos interpretativos (Figura 5). Nesta análise, as áreas em restauração ecológica, cultivo de cana-de-açúcar e vegetação nativa foram agrupadas com base no seu grau de similaridade, classificando-as em grupos homogêneos.

Figura 5 - Dendograma de distância euclidiana com base nos atributos químicos do solo nas áreas em restauração ecológica, vegetação nativa e cultivo de cana-de-açúcar

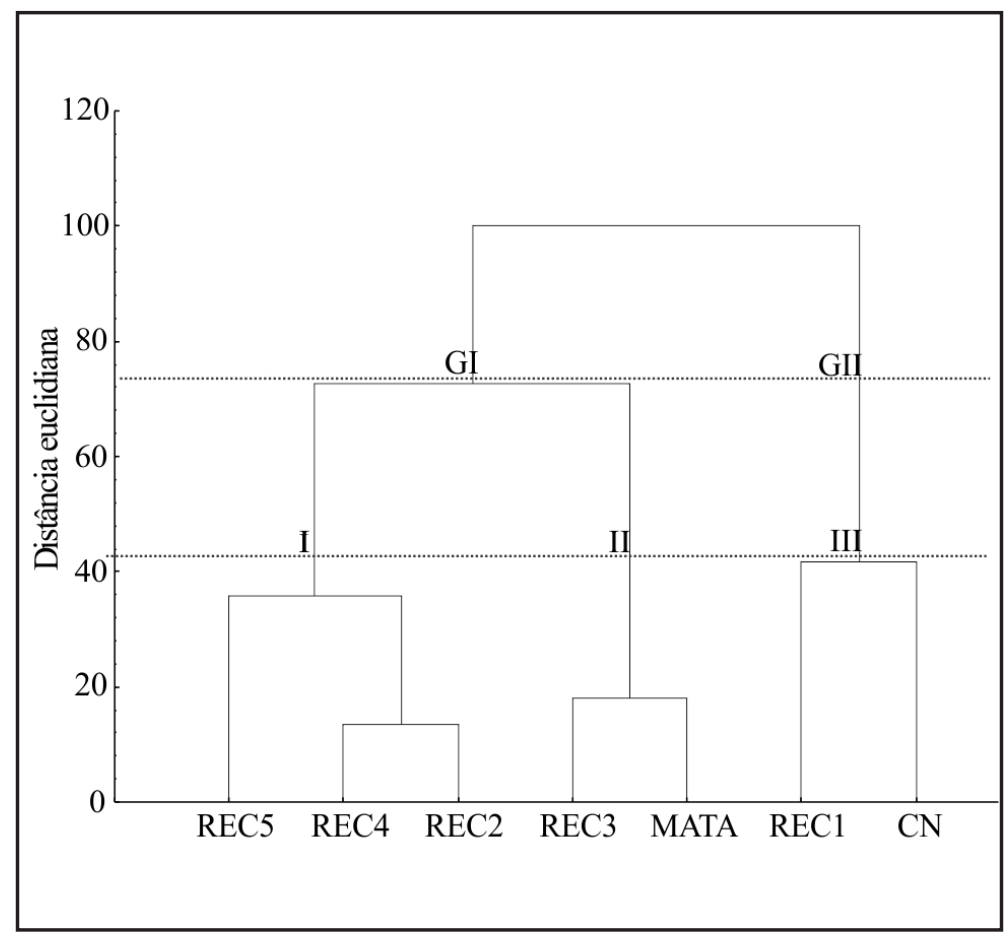

Fonte: Autores (2017)

Em que: $\mathrm{REC1}$ = área em restauração ecológica 1; $\mathrm{REC2}$ = área em restauração ecológica 2; $\mathrm{REC3}$ = área em restauração ecológica 3; REC4 = área em restauração ecológica 4; REC5 = área em restauração ecológica 5; CN = cana-de-açúcar; MATA = fragmento de vegetação nativa.

$\mathrm{Na}$ interpretação da matriz de similaridade entre as áreas, foi admitido um corte na distância euclidiana de setenta e oito permitindo uma divisão clara de 02 (dois) grupos ordenados por meio do conjunto dos atributos químicos. O grupo 1 engloba os dados que representam as áreas em restauração (REC2, REC3, REC4, REC5) 
e vegetação nativa (MATA) e o grupo 2 formado pela área em restauração REC1 e cultivo de cana-de-açúcar (CN). Todavia, ao efetuar um corte na distância euclidiana de quarenta e dois, demonstrando as áreas que apresentam maior similaridade, houve a formação de três grupos, sendo I o grupo formado por REC2, REC4 e REC5, II o grupo representado por REC3 e MATA e III o grupo formado por REC1 e CN. A formação de grupos que apresentam maior grau de similaridade indica que o tempo de resiliência e o manejo do solo podem influenciar no comportamento dos atributos químicos do solo.

Visando a estudar o agrupamento das áreas com base no grau de similaridade, desconsiderando a separação por camadas, observa-se que as RECs, quanto aos atributos químicos do solo, estão respondendo à intervenção de restauração, considerando que quatro das cinco RECs estudadas apresentaram grande similaridade com área de vegetação nativa.

Mudanças na qualidade do solo também foram descritas por Yada et al. (2015), ao estudarem os atributos dos solos degradados por mineração de estanho e em recuperação. Por outro lado, Freitas et al. (2015) constataram que a área de vegetação nativa formou um grupo distinto da área de cana-de-açúcar e reflorestada.

A separação dos grupos, evidenciando os três diferentes usos do solo (vegetação nativa, restauração ecológica e cultivo de cana-de-açúcar), reforçam os efeitos das diferentes formas de manejo sobre a modificação nos atributos do solo. Cabe destacar que ainda que em CN o manejo implique em práticas como adubação, capaz de proporcionar melhorias em aspectos como a fertilidade, este não foi suficiente para evitar o isolamento de CN dos demais grupos sugerindo baixa correspondência com as características químicas naturais dos solos com cobertura florestal.

A distinção de agrupamento é resultado, portanto, da influência das diferenças nos atributos observados quanto às formas de manejo, possibilitando uma análise mais generalizada da qualidade do sistema solo nas áreas estudadas. Dentre os atributos, destaca-se que o cultivo da cana-de-açúcar esteve associado à redução do componente de matéria orgânica a despeito do preparo intensivo do solo e do uso de fertilizantes. 
Assim, a análise de componentes principais e a análise de agrupamento evidenciaram as diferenças e similaridades entre as áreas estudadas com base nos parâmetros químicos do solo em razão das diferentes formas de manejo. Ao se interpretar o solo sob a vegetação nativa (MATA) como modelo de referência por ser considerado um sistema mais balanceado em seus aspectos físicos, químicos e biológicos, os dados observados para as áreas em restauração (REC2, REC3, REC4 e REC5), em maior ou menor grau, se encontram mais próximas às condições observadas para MATA, sugerindo que uma nova dinâmica foi estabelecida a partir das intervenções de restauração.

Para condições similares ao presente estudo seriam oportunos trabalhos direcionados à avaliação dos efeitos do aumento no componente de matéria orgânica do solo como prática favorável na restauração. O emprego de técnicas como transposição de serapilheira, resíduo de poda e/ou incorporação de outros resíduos orgânicos associados ao plantio de mudas podem ser importantes para o aumento da qualidade do solo nestas condições.

\section{CONCLUSÕES}

Dentre as áreas manejadas para fins de reposição da cobertura vegetal nativa, a área em restauração denominada REC1 apresentou relação negativa com os atributos químicos do solo e maior similaridade com a área de cultivo de cana-deaçúcar. Em contrapartida, a área em restauração denominada REC3 apresentou maior similaridade com a área de vegetação nativa e, consequentemente, melhor qualidade química do solo. O plantio de restauração proporcionou a cobertura vegetal com espécies arbóreas nativas, o que, aliado à ausência de mecanização, implicou em maior aporte de resíduos vegetais e manutenção dos teores de matéria orgânica; elementos importantes na melhoria da qualidade do solo.

As novas formas de manejo nas áreas em restauração implicam em diferentes níveis de qualidade do sistema solo, tendendo ao aumento da estabilidade e integridade biológica, essas alterações fazem parte dos processos ecológicos comuns a ecossistemas preservados. 


\section{REFERÊNCIAS}

ALVES, S. M. F. et al. Variabilidade espacial de atributos físicos-químicos do solo usando técnica de análise de componentes principais e geoestatística. Bioscience Journal, Uberlândia, v. 30, n. 1, p. 22-30, jun. 2014.

ALVES, T. S. et al. Biomassa e atividade microbiana de solo sob vegetação nativa e diferentes sistemas de manejo. Acta Scientarum Agronomy, Maringá, v. 33, p. 341-347, 2011.

AUDEH, S. J. S. et al. Qualidade do solo: uma visão etnopedológica em propriedades agrícolas familiares produtoras de fumo orgânico. Revista Brasileira de Agroecologia, [s. 1.], v. 6, n. 3, p. 34-48, 2011.

BRASIL. Lei N 12.727, de 17 de outubro de 2012. Brasília: Presidência da República, 2012. Disponível em: http://aiba.org.br/wp-content/uploads/2014/10/Lei-12727-2012-Codigoflorestal.pdf. Acesso em: 04 fev. 2016.

CARDOSO, E. L. et al. Qualidade química e física do solo sob vegetação arbórea nativa e pastagens no Pantanal Sul-Mato-Grossense. Revista Brasileira de Ciência do Solo, Viçosa, MG, v. 35, p. 613-622, 2011.

CARNEIRO, M. A. C. et al. Atributos físicos, químicos e biológicos de solo de Cerrado sob diferentes sistemas de uso e manejo. Revista Brasileira de Ciência do Solo, Viçosa, MG, v. 33, n. 1, p. 147-157, 2009.

CASTILHOS, N. D. B. et al. X-ray fluorescence and gamma-ray spectrometry combined with multivariate analysis for topographic studies in agricultural soil. Applied Radiation and Isotopes, New York, v. 95, p. 63-71, jan. 2015.

CHERUBIN, M. R. et al. A soil management assessment framework (SMAF) evolution of brazilian sugarcane expansion on soil quality. Soil Science Society of America Journal, Madison, v. 25, p. 215-226, fev. 2016.

COELHO, A. M. Agricultura de precisão: manejo da variabilidade espacial e temporal dos solos e das culturas. In: CURI, N. et al. (ed.). Tópicos em ciência do solo. Viçosa, MG: Sociedade Brasileira de Ciência do Solo, 2003. v. 3. p. 259-290.

CORTEZ, J. W. et al. Métodos multivariados na avaliação dos atributos físicos do solo na cafeicultura irrigada. Engenharia na agricultura, Viçosa, MG, v. 19, n. 2, p. 132-140, mar./abr. 2011.

EBELING, A.G. et al. Relação entre acidez e outros atributos químicos em solos com teores elevados de matéria orgânica. Bragantia, Campinas, v. 67, n. 22, p. 429-439, 2008.

EMBRAPA. Manual de métodos de análise de solo. 2. ed. Rio de Janeiro: Ministério da Agricultura e do Abastecimento, 1997. 212 p.

EMBRAPA. Sistema brasileiro de classificação de solos. 3. ed. Brasília, DF, 2013. 342 p. 
FRANCHINI, J. C. et al. Dinâmica de íons em solo ácido lixiviado com extratos de resíduos de adubos verdes e soluções puras de ácidos orgânicos. Pesquisa Agropecuária Brasileira, Brasília, v. 34, p. 2267-2276, dez. 1999.

FREITAS, L. et al. Atributos químicos de Latossolo Vermelho submetido a diferentes manejos. Floresta, Curitiba, v. 45, n. 2, p. 229-240, abr./jun. 2015.

IBGE. Mato Grosso do Sul. Brasília, 2019. Disponível em: https://cidades.ibge.gov.br/brasil/ ms/pesquisa/14/10193?indicador=10246. Acesso em: 13 ago. 2019.

JOSÉ, J. V. et al. Análise multivariada e geoestatística de variáveis físico-hídricas de diferentes solos. Water Resources and Irrigation Management, [s. 1.], v. 2, n. 3, p. 121-129, 2013.

KAISER, H. The varimax criterion for analytic rotation in factor analysis. Psychometrika, New York, v. 23, n. 3, p. 187-200, sep. 1958.

LANDIM, P. M. B. Análise estatística de dados geológicos multivariados. São Paulo: Oficina do Texto, 2011. 208 p.

MANLY, B. F. J. Métodos estatísticos multivariados: uma introdução. 3. ed. Porto Alegre: Bookman, 2008. 229 p.

MIYAZAWA, M.; PAVAN, M. A.; CALEGARI, A. Efeito de material vegetal na acidez do solo. Revista Brasileira de Ciência do Solo, Viçosa, MG, v. 17, p. 411-416, 1993.

MORAIS, T. P. S.; PISSARRA, T. C. T.; REIS, F. C. Atributos físicos e matéria orgânica de um Argissolo Vermelho-Amarelo em microbacia hidrográfica sob vegetação nativa, pastagem e cana-de-açúcar. Enciclopédia Biosfera, Goiânia, v. 8, n. 15, p. 213-223, 2012.

MUELLER, B. C. et al. Links between plan and fungal communities across a deforestation chrono sequence in the Amazon rainforest. ISME Journal, [s. 1.], v. 8, p. 1548-1550, 2014.

NASCIMENTO, P. C. et al. Uso da terra e atributos de solos do estado do Rio Grande do Sul. Revista Brasileira de Engenharia Agrícola e Ambiental, Campina Grande, v. 18, n. 9, p. 920926, 2014.

NOVAK, E. Indicadores das condições do solo e banco de sementes de mata nativa e áreas em restauração ecológica. 2017. Tese (Doutorado em Recursos Naturais) - Universidade Estadual de Mato Grosso do Sul, Unidade Universitária de Dourados, Dourados, 2017.

NOVAK, E. et al. Chemical and microbiological attributes under different soil cover. Cerne, Lavras, v. 23, n. 1, p. 19-30, 2017.

OKSANEN, J. et al. Community ecology package: Vegan. Version 1.8.1. [S. I: s. n.], 2006.

OLIVEIRA, I. A. et al. Caracterização de solos sob diferentes usos na região sul do Amazonas. Acta amazônica, Manaus, v. 45, n. 1, p. 1-12, 2015. 
PAYE, H. S.; MELLO, J. W. V.; MELO, S. B. Métodos de análise multivariada no estabelecimento de valores de referência de qualidade para elementos-traço em solos. Revista Brasileira de Ciência do Solo, Viçosa, MG, v. 36, n. 3, p. 1031-1041, 2012.

PORTUGAL, A. F.; COSTA, O. D. V.; COSTA, L. M. Propriedades físicas e químicas do solo em áreas com sistemas produtivos e mata na região da Zona da Mata mineira. Revista Brasileira de Ciência do Solo, Viçosa, MG, v. 34, n. 2, p. 575-585, 2010.

PRAGANA, R. B. et al. Qualidade física de latossolos amarelos sob Plantio Direto na região do cerrado piauiense. Revista Brasileira de Ciência do Solo, Viçosa, MG, v. 36, p. 1591-1600, 2012.

R DEVELOPMENT CORE TEAM. R: a language and environment for statistical computing. Vienna: R Foundation for Statistical Computing, 2015. 409 p.

ROVEDDER, A. P. M. et al. Relação solo-planta em remanescente da floresta estacional decidual na Região Central do Rio Grande do Sul. Ciência Rural, Santa Maria, v. 44, n. 12, p. 2178-2185, dez. 2014.

SILVA A. F. et al. Análise multivariada na diferenciação entre manejos do solo cultivado com café. Revista Energia na Agricultura, Botucatu, v. 29, n. 1, p. 57-63, jan./mar. 2014.

SILVA, S. A. et al. Variabilidade espacial de atributos químicos de um latossolo vermelhoamarelo húmico cultivado com café. Revista Brasileira de Ciência do Solo, Viçosa, MG, v. 34, p. 15-22, 2010.

SOBRAL, A. C. et al. Natural and anthropogenic influence on soil erosion in a rural watershed in the Brazilian southeastern region. Regional Environmental Change, New York, v. 15, n. 4, p. 709-720, 2015.

SOUSA, D. M. G.; MIRANDA, L. N.; OLIVEIRA, S. A. Acidez do solo e sua correlação. In: NOVAIS, R. F. et al. Fertilidade do solo. Viçosa, MG: Sociedade Brasileira de Ciência do Solo, 2007. 1017 p.

SOUZA, R. A. et al. Effects of sugarcane harvesting with burning on the chemical and microbiological properties of the soil. Agriculture, Ecosystems and Environment, [s. I.], v. 155, p.1-6, 2012.

TEFERI, E.; BEWKWT, W.; SIMANE, B. Effects of land use and land cover on selected soil quality indicators in the headwater area of the Blue Nile basin of Ethiopia. Environmental Monitoring and Assessment, Dordrecht, v. 188, n. 2, p. 83-94, dez. 2016.

YADA, M. M. et al. Atributos químicos e bioquímicos em solos degradados por mineração de estanho e em fase de recuperação em ecossistema amazônico. Revista Brasileira de Ciências do Solo, Viçosa, MG, v. 39, p. 714-724, 2015. 


\section{Contribuição de Autoria}

\section{1 - Elaine Novak}

Bióloga, Dra., Professora

https://orcid.org/0000-0002-1027-3534•elainenovak_@hotmail.com

Contribuição: Administração do projeto, Escrita- - primeira redação, Escrita - revisão e edição

\section{2 - Laércio Alves Carvalho}

Agrônomo, Dr., Professor

https://orcid.org/0000-0003-0034-8237•laercio@uems.br

Contribuição: Supervisão

\section{3 - Etenaldo Felipe Santiago}

Biólogo, Dr., Professor

https://orcid.org/0000-0001-6838-1098•felipe@uems.br

Contribuição: Supervisão

\section{4 - Fabiane Silva Ferreira}

Bióloga, Dra., Pesquisadora Autônoma

https://orcid.org/0000-0001-9085-9799•fabianesfbio@gmail.com

Contribuição: Análise Formal

\section{5 - Marina Rodrigues Maestre}

Estatística, Dra., Professora

https://orcid.org/0000-0002-4740-1333•marina.maestre@uems.br

Contribuição: Análise Formal

\section{Como citar este artigo}

Novak, E.; Carvalho, L. A.; Santiago, E. F.; Ferreira, F. S.; Maestre, M. R. Composição química do solo em diferentes condições ambientais. Ciência Florestal, Santa Maria, v. 31, n. 3, p. 1063-1085, 2021. DOI 10.5902/1980509828995. Disponível em: https://doi.org/10.5902/1980509828995. Acesso em: xx mês-abreviado 2021. 